\title{
FOR AUTHORS
}

\section{Peer Review Process}

The procedures governing the review process of articles submitted for publication in the Copernican Journal of Finance \& Accounting meets the guidelines of the Announcement of the Ministry of Science and Higher Education from 29 May 2013 on the criteria and evaluation of scientific journals. The procedure of the review process considers the following rules:

- at least two independent Reviewers representing a scientific unit other than the one affiliated with the Author are appointed to evaluate the submitted article,

- all information identifying the Author (Authors) and Reviewers is removed and the principles of a double-blind review process are followed; in other cases the Reviewer signs a declaration on the non-occurrence of a conflict of interest; a conflict of interest is defined here as any direct personal relationship holding between the Reviewer and the Author (in particular, such relationships as kinship of the second degree, or marriage), relationships resulting from professional dependence or from any scientific cooperation conducted within two years preceding the year in which the review was made,

- a written review explicitly states the conditions on which an article should be accepted for publication or informs of rejection,

- the qualification criteria and a review form are available at the journal's website,

- names of Reviewers who evaluated specific publications or issues are not disclosed.

Based on the evaluations received from Reviewers the Editorial Board decides whether the article should be accepted for publishing, rejected or returned to the Author for revision. 
After the reception of the Reviewers' comments, the Author is obliged to respond within a time period specified by the Editorial Board. Failure to meet a specified deadline will be deemed as resignation from publication.

\section{Focus AND SCOPE OF THE JOURNAL, ITS TARGET GROUP AND RULES OF COOPERATION WITH AUTHORS}

The Copernican Journal of Finance \& Accounting is a scientific journal created by the Department of Finance Management and the Department of Accounting in the Faculty of Economic Sciences and Management of Nicolaus Copernicus University in Torun. The Journal serves for the development of the science of Finance as a forum of presentations and analyses of scientific working papers in the scope of finance and accounting in the international dimension. It is dedicated to theoreticians and also practitioners who decided to meet a challenge of obtaining scientific degrees in Finance.

Since 2014, the Copernican Journal of Finance \& Accounting publishes articles (in English language only) on issues related to finance and accounting. Articles submitted for publication should be original and not published anywhere before and should not be the subject of any qualification procedure for publication in any other journal of any other publisher. In accordance with the guidelines of the Announcement of the Ministry of Science and Higher Education from 2 June 2015 on the criteria and evaluation of scientific journals submitted texts should be scientific works, which means an article presenting the outcome of original research that is empirical, theoretical, technical, or analytical in its nature and containing the title of the publication, Authors' names with their affiliation, presenting the current state of knowledge, research methodology, the course of the research process with its results and conclusions, and the literature cited in it (bibliography).

A condition for accepting a text for the publishing process entails following absolutely the editorial standards included in the Editorial requirements file as well as sending in to the address of the Editorial Office a completed and legibly signed submission form.

Articles that do not fulfil the formal requirements will not be accepted for editorial processing and the materials sent in will not be returned to the Authors.

The text of the article should be sent in only in electronic form through the UMK journals platform or to the following e-mail address: cjfa@umk.pl within the specified time frame (sending a printed version of the article is not neces- 
sary). Any graphs, figures, etc. that constitute part of the electronic text must be included in separate files (for instance, in Excel files). An Author submitting an article electronically will receive email confirmation of acceptance and of entering the review process.

The Editorial Board reserves the right to choose articles for publication in the Copernican Journal of Finance \& Accounting and to shorten the text and make amendments in it without the Author's consent. The criteria for selection are the quality and the subject relevance to finance and accounting.

After receiving confirmation of acceptance for publishing, the Author should send in a printed and signed Agreement with the Author to publish an article. Authors of articles published in the Copernican Journal of Finance \& Accounting do not receive any financial payment.

The detailed editorial requirements are outlined on the website of the Journal http://wydawnictwoumk.pl/czasopisma/index.php/CJFA/about/submissions\#authorGuidelines. Authors are asked to find out whether specific bibliographical entries have their DOI numbers. DOI numbers can be checked on the website: http://www.crossref.org/guestquery/

\section{Publication ETHICS}

With a view to ensuring scientific reliability the Editorial Board of the Copernican Journal of Finance \& Accounting makes efforts to publish works that meet ethical norms applied in science. In accordance with the recommendations of the Ministry of Science and Higher Education any cases of unreliability and dishonesty (e.g., 'ghostwriting' and 'guest authorship') identified by the Editorial Board will be documented and exposed by informing appropriate bodies (institutions employing Authors).

Explanations of the terms 'ghostwriting' and 'guest authorship' as defined by the Ministry of Science and Higher Education (source: http://www.nauka. gov.pl/):

- 'Ghostwriting' is qualified cases in which someone has made a substantial contribution to publication, without revealing his participation as one of the authors, or without being mentioned in the acknowledgments included in the publication.

- 'Guest authorship' ('honorary authorship') happens when someone did not contribute at all or hardly contributed to the creation of a publica- 
tion; however, despite that fact his/her name is provided as an author/ co-author of the publication.

In order to prevent such unfair practices each submitted article with more than one Author should be accompanied by a declaration filled in and signed by the Authors. The declaration is intended to eliminate cases of 'ghostwriting' and 'guest authorship' (the declaration is part of the submission form).

In the case of a submitted article which during its preparatory phase was supported financially by an external institution, the Author is obliged to insert information about such a fact in the Introduction of the article.

Editorial Office

Copernican Journal of Finance \& Accounting

ul. Gagarina 13a, 87-100 Toruń

phone + 48566114634 (contact mgr Agnieszka Żołądkiewicz)

fax +48566542493

cjfa@umk.pl

www.cjfa.umk.pl 